RESIDENT

\& FELLOW

SECTION

Section Editor

Mitchell S.V. Elkind,

MD, MS

Markos Poulopoulos, MD

David Silvers, MD

Address correspondence and reprint requests to $\mathrm{Dr}$. Poulopoulos Markos, Department of Neurology, Hartford Hospital and University of Connecticut School of Medicine, 80 Seymour Street, Hartford, CT 06102-5037 markpou@hotmail.com

\title{
Clinical Reasoning: A video analysis of eye and limb movement abnormalities in a parkinsonian syndrome
}

\section{的}

\section{SECTION 1}

A 72-year-old right-handed man with a history of coronary artery disease, aortic valve replacement, and hypothyroidism presented with 3 years of progressive difficulty using his right upper extremity, which had resulted in a largely nonfunctional limb within a year. In contrast, he reported relatively intact left upper limb function. He had developed gait instability within 6 months of onset and by 2 years he was nonambulatory. He reported slurring of speech and difficulty moving his eyes to either side, but especially to the right. He denied visual loss, diplopia, cognitive decline, visual hallucinations, sensory loss, autonomic symptoms, sleep disturbance, or perception of an alien limb. There had only been a nonsustained levodopa response. His medications included atenolol, monopril, simvastatin, warfarin, and levothyroxine. There was no family history of neurologic disease. He denied toxic exposures and had a distant history of tobacco use.

On examination, he was not orthostatic. He was fully oriented, could recite the months backwards, and had fluent speech and normal comprehension and naming. He recalled 2 out of 3 words after 5 minutes. He accurately drew a clock. He required 3 attempts to correctly imitate the Luria 3-step test (normal $\leq 2$ attempts) and he could not sustain the sequence. The go-no go task consistently showed errors of commission and he was concrete with proverb interpretation.

He had abnormal eye movements (videos on the Neurology ${ }^{\circledR}$ Web site at www.neurology.org) and minimal dysarthria. He had mild hypophonia, a reduced blink rate, and bilateral lead pipe rigidity, greater on the right. Strength was full. There was no tremor or myoclonus. Additional motor features are demonstrated on the videos. He had normoactive reflexes and flexor plantar responses. While primary modality sensation was normal, he had bilaterally impaired 2-point discrimination, right hand astereognosis, and agraphesthesia, without extinction to double simultaneous touch. No cerebellar signs were appreciated. He was able to stand only with assistance. He had a stooped, rigid posture, was unable to initiate steps, and retropulsed when unsupported.

$$
\text { A brain MRI was unremarkable. }
$$

\section{Question for consideration:}

1. What are the main diagnostic considerations? 
SECTION 2

The videos were taken 3 years into his illness.

Questions for consideration after review of videos:

1. What eye movement abnormalities are seen on the videos?
2. What is the significance of head movements during saccadic testing?

3. What are the motor abnormalities exhibited?

GO TO SECTION 3 


\section{SECTION 3}

The initial section of the first video demonstrates abundant square-wave jerks (SWJ), which are saccadic intrusions on fixation. Subsequently, saccadic pursuit is shown, horizontally and vertically. A very mild upgaze paresis may be appreciated, which is not overcome by the vestibulo-ocular reflex. The second section illustrates optokinetic nystagmus (OKN) testing: quick phases are preserved horizontally, but are less robust vertically. Small and large amplitude saccades are tested on cue and then self-paced. Although not shown, the patient could not initiate saccades when his head was fully stabilized. In the video segment, although the patient was instructed to look at a target without turning his head, he could only initiate saccades with a head thrust, sometimes accompanied by a blink. Horizontal saccadic latency was increased bilaterally, more to the right. The difficulty initiating voluntary horizontal saccades with preserved reflex saccades (i.e., normal horizontal OKN quick phases) defines ocular motor apraxia.

The second video demonstrates a dystonic right hand, with wrist and finger flexion. Dystonia describes sustained muscle contractions, repetitive

Table Comparison of eye movement abnormalities in progressive supranuclear palsy (PSP) vs corticobasal degeneration (CBD)

\begin{tabular}{|c|c|c|}
\hline & PSP & CBD \\
\hline \multirow{3}{*}{$\begin{array}{l}\text { Supranuclear } \\
\text { ophthalmoplegia }\end{array}$} & - Prominent & - Less prominent \\
\hline & - May be late feature & - Often late feature \\
\hline & $\begin{array}{l}\text { - Vertical plane affected first } \\
\text { (especially downgaze) and } \\
\text { disproportionate to horizontal }\end{array}$ & \\
\hline \multirow{2}{*}{$\begin{array}{l}\text { Horizontal saccadic } \\
\text { velocity }\end{array}$} & - Impaired later & - Impaired later (hypometric) \\
\hline & - Slow & \\
\hline \multirow{3}{*}{$\begin{array}{l}\text { Vertical saccadic } \\
\text { velocity }\end{array}$} & - Impaired early & - Impaired later (hypometric) \\
\hline & - Slow, especially downgaze & \\
\hline & - Small, hypometric saccades & \\
\hline \multirow{2}{*}{$\begin{array}{l}\text { Square-wave jerks } \\
\text { (greater than 10-12 } \\
\text { times per minute) }\end{array}$} & - Very prominent & $\begin{array}{l}\text { - Usually less prominent } \\
\text { and seen late }\end{array}$ \\
\hline & - Frequent feature & \\
\hline \multirow[t]{2}{*}{ Saccadic latency } & - Usually normal & $\begin{array}{l}\text { - Delayed initiation, first } \\
\text { horizontal (i.e., worse to the } \\
\text { side of greater apraxia) }\end{array}$ \\
\hline & & - Ocular motor apraxia \\
\hline \multirow[t]{4}{*}{ Optokinetic nystagmus } & $\begin{array}{l}\text { - Impaired generation } \\
\text { of quick phases }\end{array}$ & - Usually retained \\
\hline & $\begin{array}{l}\text { - Vertical plane affected first, } \\
\text { especially downgaze }\end{array}$ & \\
\hline & - May occur early & \\
\hline & $\begin{array}{l}\text { - Precedes supranuclear } \\
\text { ophthalmoplegia }\end{array}$ & \\
\hline Antisaccadic movements & - Abnormal & $\begin{array}{l}\text { - Accurate, but increased } \\
\text { latency }\end{array}$ \\
\hline
\end{tabular}

twisting movements, and abnormal postures. There is right greater than left upper extremity bradykinesia (while not shown, fine finger movements are also bradykinetic). Note left hand mirror movements, which are contralateral involuntary overflow movements in homologous muscles that accompany voluntary activity. The left hand is also apraxic while attempting a transitive task (i.e., with tool use). Apraxia is the failure to perform a learned act that cannot be otherwise explained, such as secondary to a comprehension or sensorimotor deficit. As he could not approximate tasks with his right hand-possibly due to bradykinesia or dystonia - one must be cautious in applying the term apraxia in this case. The authors speculate that the patient's right arm drift may be a manifestation of an alien limb phenomenon.

DISCUSSION Although idiopathic Parkinson disease is the most common cause of progressive asymmetric parkinsonism, the relatively brisk course, limb and oculomotor apraxia, cortical sensory loss, early postural instability, and nonsustained levodopa response all strongly suggest an alternative parkinsonian syndrome. We considered the nonacute course and absence of confusion incompatible with a potentially treatable autoimmune encephalopathy (Hashimoto disease). The abnormal saccades and absence of dysautonomia, dementia, visual hallucinations, and dream enactment behavior render unlikely the synucleinopathies multiple system atrophy and dementia with Lewy bodies. The tauopathies corticobasal degeneration (CBD) and progressive supranuclear palsy (PSP) are the primary considerations in a patient with parkinsonism and significantly abnormal eye movements (table).

This patient's most striking eye movement abnormality is the ocular motor apraxia. First described by Cogan in 1953, ocular motor apraxia is postulated to result from disruption of descending pathways from the frontal and parietal eye fields to the superior colliculus and brainstem reticular formation. The congenital form is often associated with ataxia, as in ataxia oculomotor apraxia. ${ }^{1}$ Acquired oculomotor apraxia can be seen acutely after frontoparietal strokes, or in progressive disorders such as Huntington disease and CBD. ${ }^{1}$ Saccadic latencies are consistently increased in CBD (indicating dysfunction of the posterior parietal cortex), greater toward the more apractic side (as seen in this case), while decreased saccadic velocities are seen in PSP. ${ }^{2,3}$ While this patient's horizontal saccadic velocity was judged normal, typical of CBD, this could be confirmed with eye movement recordings. ${ }^{2}$

SWJ are small, paired, horizontal conjugate saccades, which move the eyes away from fixation with a brief intersaccadic interval, occurring normally up to 
10-12 times per minute. ${ }^{4}$ That this patient has more than 40 SWJ per minute is clearly pathologic. SWJ are due to dysfunction of the superior colliculus and its connections with the mesencephalic reticular formation or the inhibitory input from the substantia nigra, pars reticulata. SWJ are prominent in Friedreich ataxia and PSP, but have been reported in several extrapyramidal disorders, including late in CBD. ${ }^{1,3}$ Saccadic pursuit is similarly nonspecific. ${ }^{5}$ Supranuclear ophthalmoplegia disproportionately affecting downgaze is the hallmark of PSP, although it may occur late or be absent, whereas impaired downward saccades are typically seen early. ${ }^{3,6}$ Supranuclear ophthalmoplegia is less common in CBD, and is generally a late finding. ${ }^{6,7}$ The relatively sparse vertical OKN quick phases may be one point favoring PSP.

Limb kinetic and ideomotor apraxia (IMA) are the 2 types of apraxia most relevant to CBD. In limb kinetic apraxia, which localizes to the frontoparietal cortex, there is a loss of dexterity. IMA, which localizes to parietal association areas, and less frequently to the supplementary motor cortex and basal ganglia, is characterized by complex spatial and temporal errors. IMA is primarily caused by left hemispheric lesions, often producing bilateral, asymmetric deficits. This patient exhibited the spatial organization errors typical of IMA. Although apraxia is one of the major clinical criteria of CBD (most commonly IMA), it can also be a feature of PSP. ${ }^{3}$

This patient has a persistent right hand dystonia, which in CBD classically becomes fixed. Mirror movements may occur during normal childhood development, but also may be found in various congenital and acquired conditions. For example, mirror movements may develop after a stroke or occur in conditions causing asymmetric parkinsonism such as PD or CBD. ${ }^{8}$ This patient exhibited cortical sensory loss, a core feature of CBD. ${ }^{7,9}$ An alien limb phenomenon is present in about $50 \%$ of CBD cases. ${ }^{9}$

Notwithstanding the diminished vertical OKN quick phases, based on the cortical and basal ganglia clinical signs-IMA, cortical sensory loss, asymmetric bradykinesia and rigidity, hand dystonia, mirror movements, and increased horizontal saccadic latency with oculomotor apraxia-CBD is the best clinical diagnosis. ${ }^{9,10}$ Other common findings include apathy, executive dysfunction (as seen in this patient), aphasia/apraxia of speech, yes/no reversals, myoclonus, and an irregular, jerky action and postural tremor. ${ }^{7}$

As CBD progresses, brain MRI may show asymmetric frontoparietal cortical atrophy (more prominent contralateral to the more clinically affected side), whereas atrophy primarily affects the midbrain in PSP. Functional imaging has also been applied to help distinguish CBD from PSP. ${ }^{9}$ Clinicopathologic studies have shown that the positive predictive value of $\mathrm{CBD}$ clinical criteria is only around $50 \% .{ }^{10}$ Autopsy studies have confirmed that PSP, Alzheimer disease, frontotemporal dementia, and even Creutzfeldt-Jakob disease can cause a CBD-like clinical picture. As there is significant clinical overlap between CBD and PSP, a definitive diagnosis of $\mathrm{CBD}$ can only be made pathologically. ${ }^{7,10}$ Typical features include neuronal loss and gliosis with superficial spongiosis, tau-positive neuronal and glial inclusions - astrocytic plaques (the most specific finding), oligodendroglial coiled bodies, and achromatic neurons-mostly in the superior frontal and parietal gyrus, sensorimotor cortex, and striatum. ${ }^{10}$

As neurologists are better at making an anatomic than pathologic diagnosis, it may be more appropriate to refer to the corticobasal syndrome or PSP syndrome..$^{7,10}$

This case of corticobasal syndrome, a rare sporadic cause of parkinsonism, underscores the importance of carefully examining eye movements and performing a detailed motor examination, in order to arrive at an accurate topographic, if not pathologic diagnosis.

\section{DISCLOSURE}

Dr. Silvers has received unrestricted type financial support for neurology resident education from Teva Neuroscience, Pfizer, and Merck. Dr. Poulopoulos reports no disclosures

\section{REFERENCES}

1. Leigh J, Zee D. The Neurology of Eye Movements, 4th ed. Oxford; 2006.

2. Rivaud-Pechoux S, Vidailhet M, Gallouedec G, Litvan I, Gamar B, Pierrot-Deseilligny C. Longitudinal ocular motor study in corticobasal degeneration and progressive supranuclear palsy. Neurology 2000;54:1029-1032.

3. Zadikoff C, Lang AE. Apraxia in movement disorders. Brain 2005;128:1480-1497.

4. Shallo-Hoffmann J, Sendler B, Muhlendyck H. Normal square wave jerks in differing age groups. Invest Ophthalmol Vis Sci 1990;31:1649-1652.

5. Rottach KG, Riley DE, DiScenna AO, Zivotofsky AZ, Leigh JR. Dynamic properties of horizontal and vertical eye movements in parkinsonian syndromes. Ann Neurol 1996;39:368-377.

6. Brooks DJ. Diagnosis and management of atypical parkinsonian syndromes. J Neurol Neurosurg Psychiatry 2002; 72:i10-i16.

7. Boeve BF, Lang AE, Litvan I. Corticobasal degeneration and its relationship to progressive supranuclear palsy and frontotemporal dementia. Ann Neurol 2003;54:S15-S19.

8. Espay AJ, Li J-Y, Johnston L, Chen R, Lang AE. Mirror movements in parkinsonism: evaluation of a new clinical sign. J Neurol Neurosurg Psychiatry 2005;76:1355-1359.

9. Stover NP, Watts RL. Corticobasal degeneration. Semin Neurol 2001;21:49-58.

10. Lang AE. Corticobasal degeneration: selected developments. Mov Disord 2003;18:S51-S56. 


\section{Neurology}

\section{Clinical Reasoning: A video analysis of eye and limb movement abnormalities in a parkinsonian syndrome}

Markos Poulopoulos and David Silvers

Neurology 2009;73;e20-e23

DOI 10.1212/WNL.0b013e3181b04ab7

This information is current as of August 3, 2009

\section{Updated Information \&} Services

Supplementary Material

References

Permissions \& Licensing

Reprints including high resolution figures, can be found at: http://n.neurology.org/content/73/5/e20.full

Supplementary material can be found at: http://n.neurology.org/content/suppl/2009/08/02/73.5.e20.DC1

This article cites 9 articles, 4 of which you can access for free at: http://n.neurology.org/content/73/5/e20.full\#ref-list-1

Information about reproducing this article in parts (figures,tables) or in its entirety can be found online at:

http://www.neurology.org/about/about_the_journal\#permissions

Information about ordering reprints can be found online:

http://n.neurology.org/subscribers/advertise

Neurology ${ }^{\circledR}$ is the official journal of the American Academy of Neurology. Published continuously since 1951, it is now a weekly with 48 issues per year. Copyright . All rights reserved. Print ISSN: 0028-3878. Online ISSN: 1526-632X.

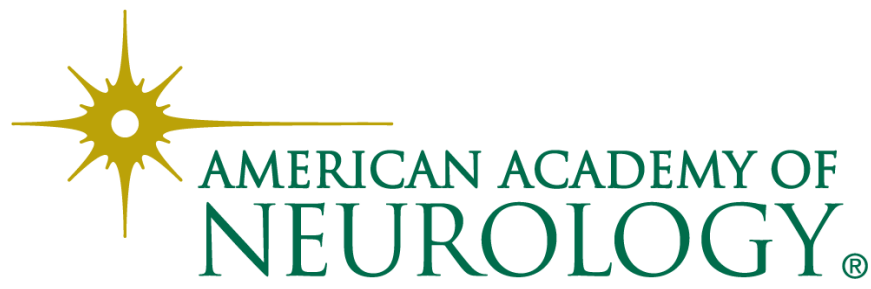

